\section{Rural Community Gardens Capacity to Increase Accessibility and Affordability of Healthy Foods in Alabama}

\section{Abstract}

Context: Urban community gardens have been shown to make healthy foods more accessible and affordable. There is limited research available, however, regarding the influence of rural community gardens, where populations consume less fruits and vegetables and often travel further and pay more for healthy food.

Objective: To evaluate rural community gardens' abilities to increase accessibility and affordability of healthy foods through measurement of harvest weights and conversions to edible portion serving sizes and harvest values

Design: Longitudinal pilot study

Setting: Six geographically dispersed counties throughout Alabama during one fall production cycle

Participants: Nine established rural community gardens

Main outcomes measured: Production capabilities were measured as harvest weight, in pounds and ounces, which also were converted to edible portion serving sizes. Harvest values were calculated using harvest weights and the average retail prices for harvested produce.

Results: At conclusion of the three-month growing season, the nine rural community gardens in this study yielded 19 different varieties of vegetables weighing a total of $2,708.71$ pounds and valued at $\$ 3,788.22$. This equated to $15,110.64$ servings of vegetables, which is enough for 33 adults to meet the USDA daily vegetable recommendations during the three-month growing season.

Conclusions: Findings from this study demonstrate by growing fresh vegetables, rural community gardens can increase the accessibility and affordability of healthy foods. This data suggests rural community gardens also may have a role in improving overall health and nutrition of rural populations.

Keywords: Rural; Community gardens; Production capabilities; Harvest values; Accessibility and affordability
Megan Henning ${ }^{1}$, Ruth Brock², Barb Struempler², Sondra Parmer ${ }^{2}$, Katie Funderburk ${ }^{2}$ and Alicia Powers ${ }^{3 *}$

1 Tri-County Health Department, USA

2 Alabama Cooperative Extension System, Duncan Hall, Auburn University, USA

3 Hunger Solutions Institute, College of Human Sciences, Auburn University, USA

\section{*Corresponding author: Alicia Powers}

झ arp0042@auburn.edu

Director Strategy and Policy, Hunger Solutions Institute, College of Human Sciences, Auburn University, 334B Spidle Hall Auburn University, AL 36849, USA

Tel: (334)844-3780

Citation: Henning M, Brock R, Struempler B, Parmer S, Funderburk K, et al. (2018) Rural Community Gardens Capacity to Increase Accessibility and Affordability of Healthy Foods in Alabama. J Food Nutr Popul Health Vol.2 No.2:14

Received: December 07, 2018; Accepted: December 19, 2018; Published: December 26, 2018

\section{Introduction}

Community gardens have existed for more than 250 years. They are thought to be direct descendants of the allotment gardens in Europe; however, the modern movement is more rooted in the victory gardens of World Wars I and II [1]. In 1942, more than 15 million victory gardens yielded more than 7.5 billion pounds of food [2]. As time passed and memories of the depression and wars faded, so did victory gardens. In the 1970s, the community garden movement experienced a resurgence, with every state in the United States having some type of community garden program [1]. In 2018, the American Community Gardening Association reported more than 18,000 community gardens in the United States and Canada [3]. While this is far fewer than the amount of victory gardens, these modern community gardens have been shown to improve accessibility and affordability of healthy foods [4-9], increase fruit and vegetable consumption [4,8-13], increase physical activity [9-14] and provide numerous social $[9,15,16]$ and psychological $[9,13,14]$ benefits for both the gardeners and the community; these myriad of benefits suggest 
community gardens may be a promising strategy in addressing many public health problems [17].

Documented evidence indicates community gardens increase access to healthy foods [4-9]. In one growing season, garden plots in Laramie, Wyoming, produced an average of $128 \mathrm{lbs}$ of vegetables per $253 \mathrm{sq} \mathrm{ft}$, which provided enough daily vegetable servings for one adult for nine months [5]. Increase in access to healthy foods also was seen in San Jose, California, where 10 community garden plots, varying from 100 to $600 \mathrm{sq} f \mathrm{ft}$ in size, produced an average of $292 \mathrm{lbs}$ of produce in one growing season [4]; and in New York City where 67 gardens, totaling 1.7 acres, produced more than $87,000 \mathrm{lbs}$ of produce in a season [6].

An additional benefit of community gardens is increased affordability of fresh produce [4-6]. In 10 community garden plots in San Jose, California, each plot's produce yield had an average value of $\$ 435$ in a four-month growing season [4]. Similarly, produce from community garden plots in Laramie, Wyoming, had an average value of $\$ 401$ to $\$ 459$ per plot in a single growing season [5]. In New York City, the value of yielded produce was even greater; yields from 67 community gardens in New York City had an estimated value of more than $\$ 200,000$ [6]. Self-reported financial benefits were indicated by $58.9 \%$ of rural Missouri participants working in a community garden at least once a week stating they subsequently spent less money on food [7]. By providing a space to grow fruits and vegetables rather than purchase from food stores, community gardens provide a means to making healthful food more accessible and affordable.

Interestingly the increase in accessibility and affordability to healthy foods provided by community gardens is not restricted just to gardeners. Both urban [13] and rural $[5,7,8]$ studies reported gardeners sharing their produce with neighbors, friends and local charity organizations. Thus, not only are community gardens making a wide variety of healthy foods more accessible and affordable for gardeners, gardens also are making these foods more available for all members of the community. Therefore, the benefits of increased accessibility and affordability of healthy foods extends to non-garden members as well.

A growing body of evidence demonstrates the increase in accessibility and affordability of fresh fruits and vegetables provided by community gardens contributes to increased fruit and vegetable consumption [4,8-13]. A study in Flint, Michigan [10], found household members who participated in community gardens consumed 1.4 times more fruits and vegetables than those who did not. A study in Denver, Colorado [11], found 56\% of community gardeners met daily recommendations for fruit and vegetable consumption compared to $25 \%$ of non-gardeners $(\mathrm{P}<0.05)$. Similar increases were seen in rural populations. A study in rural lowa [8] found access to a garden of any type significantly increased the likelihood of meeting the daily vegetable recommendations $(P=0.002)$. These findings have implications on many public health problems prevalent in today's society, specifically chronic disease and obesity.

Chronic disease and obesity are complex problems and are especially widespread in rural communities. Data from the US Centers for Disease Control and Prevention's (CDC) Behavioral Risk Factor Surveillance System [17] have shown rural residents have an $8.6 \%$ higher prevalence of diabetes and $38.8 \%$ higher prevalence of heart disease than urban residents $(P=0.001$ and $P<0.001$, respectively). Similarly, an analysis of NHANES data [18] found significantly more rural adults were obese compared to urban adults (39.9\% and $33.4 \%$ respectively, $P<0.01$ ). However, research has shown higher fruit and vegetable consumption is associated with decreased risk of chronic disease and obesity $[19,20]$. Unfortunately, rural residents consume less fruits and vegetables than urban adults [21] perpetuating their health problems. Furthermore, rural residents often have to travel farther to food stores [20], and often the closest food store is a convenience store $[22,23]$. Unlike grocery stores, convenience stores usually have limited quantities of healthy foods; healthy foods available are often significantly more expensive than the same product in a grocery store $[23,24]$.

Community gardens offer a possible way to address barriers and increase accessibility and affordability of healthy foods, and ultimately, increase daily fruit and vegetable consumption of rural residents. However, the majority of research regarding benefits of community gardens has focused on urban areas.

The purpose of this pilot study is to describe production capabilities and harvest values of rural community gardens in Alabama during one fall production cycle. Findings of this study will inform the capacity of rural community gardens in addressing barriers to healthy eating and guide future studies in determining the impact rural community gardens may have in improving fruit and vegetable consumption of rural populations.

\section{Methods}

\section{Research design}

This longitudinal pilot study measured production capabilities and harvest values of rural community gardens in Alabama for the fall 2017 production cycle. Production capabilities were measured as harvest weight, in pounds and ounces, which also were converted to edible portion serving sizes. Harvest values were calculated using harvest weights and the average retail prices of produce.

\section{Population/Sample}

Researchers used a purposive sample of nine, established, rural community gardens in six counties throughout Alabama. Rural was defined, using the US Census Bureau's definition, as an area with a core metropolitan area of less than 50,000 people [25]. The recruited gardens represented diversity based on: geographical location, size and type of garden and variety of crops grown. Gardens which did not have a fall production cycle were excluded.

\section{Instrumentation}

General characteristics of rural community gardens were obtained using a Garden Information Form developed by the researchers. The form included nine questions and was completed by the community garden leader.

Each garden used a Rubbermaid ${ }^{\circledR}$ Dial Hanging Scale with Tare and a Taylor $^{\circledR}$ 20lb Hanging Scale Platform to weigh produce to 
the nearest ounce. Accuracy of the scale was predetermined by Rubbermaid $^{\circledR}$ at the checkpoint of 10 lbs with a tolerance of + $20 z$ [26]. The scale and scoop were maintained in a permanent weigh station or on a portable scale stand where both were locked to support calibration maintenance.

Harvest data were recorded using Harvest Information Forms created by the researchers. Information collected included collection date, crop harvested and weight in pounds and ounces.

\section{Procedures}

The university's Institutional Review Board deemed the study protocol as not constituting "human subjects research". Garden Information Forms were distributed to community garden leaders in July 2017. The community garden leaders were given two weeks to complete and return the form to the researchers.

Harvested crop weights were collected from the middle of September to the middle of December. Harvesters received training on weighing crops harvested and using the Harvest Information Forms to record crop weights. Blank Harvest Information Forms were kept in a weather proof box at each garden and were to be completed each time crops were harvested. Once completed, the forms were placed in a separate weather proof box. Community garden leaders retrieved completed forms and submitted them to a local data entry clerk on a monthly basis.

Researchers developed a spreadsheet for each garden where data entry clerks entered data from Harvest Information Forms. Weight data were entered by garden, date and crop. To ensure accuracy of data entry, the data entry clerks participated in a virtual training on how to access the spreadsheet on the organization's internal website and properly enter data. To calculate serving size, researchers converted each vegetable's harvest weight to edible portion by multiplying by yield percentage from USDA's Food Buying Guide for Child Nutrition Programs [27]. Once the edible portion weight was calculated, researchers used USDA's Food Composition Database [28] to determine the number of servings provided by a specific weight for each vegetable.

To tabulate harvest value, data for price per pound of a specific vegetable during the harvest season were determined from the USDA's Agricultural Marketing Services for the Southeast United States [29]. The average prices for okra, peas and turnips were not available on this resource; therefore researchers went to a local retail outlet to determine the cost rural residents paid per pound. Information on harvest values were tabulated by multiplying collected harvest crop weights by average price per pound.

\section{Statistics}

Appropriate descriptive statistics were used to summarize data. Determination of harvest weights, serving sizes and values were determined for each garden, as well as, for the aggregate and average of included gardens.

\section{Results}

Nine gardens totaling 1.85 acres were included in this study.
Among the gardens, four were raised bed gardens, and five were row gardens (Table 1). Throughout the fall production cycle, partnering gardens produced 19 different vegetables, with greens yielding the greatest weight followed by sweet potatoes and peas (Table 2).

The nine community gardens in this study yielded $2,708.71 \mathrm{lbs}$ of vegetables valued at $\$ 3,788.22$ in a single three-month fall growing season. Edible yield (74\%) totaled 2,012.91 lbs. When converted to serving sizes, this equated to $15,110.64$ servings of edible vegetables. Table 3 provides details on total harvest weights, serving sizes and values.

Each garden's vegetable production varied. On average, each garden produced $301 \mathrm{lbs}$ of unprocessed vegetables valued at $\$ 470.82(\$ 0.91 / \mathrm{lb})$. When converted to edible yield, each garden produced an average of $223.66 \mathrm{lbs}$ of raw, ready to cook or eat vegetables which equates to an average of $1,678.96$ servings of vegetables per garden. Table 3 summarizes the average production capabilities and harvest values during a fall production cycle for the nine community gardens in this study.

Table 1 Descriptive characteristic of nine rural community gardens.

\begin{tabular}{|c|c|c|c|}
\hline Garden & Type of garden & $\begin{array}{c}\text { Size (acers or } \\
\text { Sq ft ) }\end{array}$ & $\begin{array}{c}\text { Number of } \\
\text { vegetables grown }\end{array}$ \\
\hline $\mathbf{1}$ & Raised Bed $(\mathrm{n}=4)$ & $128 \mathrm{sq} \mathrm{ft}$ & 6 \\
\hline $\mathbf{2}$ & Raised Bed $(\mathrm{n}=8)$ & $256 \mathrm{sq} \mathrm{ft}$ & 3 \\
\hline $\mathbf{3}$ & Raised Bed $(n=10)$ & $320 \mathrm{sq} \mathrm{ft}$ & 5 \\
\hline $\mathbf{4}$ & Raised Bed $(n=53)$ & $1,696 \mathrm{sq} \mathrm{ft}$ & 10 \\
\hline $\mathbf{5}$ & Row & 0.05 acres & 1 \\
\hline $\mathbf{6}$ & Row & 0.25 acres & 4 \\
\hline $\mathbf{7}$ & Row & 0.25 acres & 1 \\
\hline $\mathbf{8}$ & Row & 0.50 acres & 1 \\
\hline $\mathbf{9}$ & Row & 0.75 acres & 4 \\
\hline
\end{tabular}

Table 2 Total weight for each type of vegetable grown at nine rural community gardens.

\begin{tabular}{|c|c|}
\hline Vegetables & Weight (lbs) \\
\hline Beans & 4.5 \\
\hline Beets & 2.63 \\
\hline Broccoli & 12.5 \\
\hline Brussel Sprouts & 60 \\
\hline Cabbage & 8.63 \\
\hline Carrots & 9.38 \\
\hline Cauliflower & 1.5 \\
\hline Greens & $1,058.13$ \\
\hline Lettuce & 15.19 \\
\hline Okra & 106 \\
\hline Onion & 1 \\
\hline Peas & 280 \\
\hline Peppers & 64.5 \\
\hline Pumpkins & 182 \\
\hline Radishes & 2.5 \\
\hline Squash & 3 \\
\hline Sweet Potatoes & 815 \\
\hline Tomatoes & 62.13 \\
\hline Turnips & 20.13 \\
\hline
\end{tabular}

aGreens included collard greens, mustard greens, turnip greens, Swiss chard and kale. 
Table 3 Weight, edible portion, servings and cost savings of nine rural community gardens.

\begin{tabular}{|c|c|c|c|c|c|}
\hline Garden & Weight Produced (lbs) & $\begin{array}{l}\text { Edible Portion } \\
\text { Produced (lbs) }\end{array}$ & Total Edible Servings ${ }^{b}$ & Total Value (\$) & Value/lb (\$) \\
\hline \multicolumn{6}{|l|}{ Raised Bed } \\
\hline 1 & 20.44 & 15.32 & 128.22 & 23.68 & 0.86 \\
\hline 2 & 21.64 & 17.29 & 115.21 & 21.67 & 1 \\
\hline 3 & 27.82 & 21.52 & 167.91 & 31.34 & 0.89 \\
\hline 4 & 175.81 & 144.37 & 936.03 & 216.13 & 0.81 \\
\hline Subtotal ${ }^{c}$ & 245.71 & 198.49 & $1,347.37$ & 292.82 & 3.56 \\
\hline \multicolumn{6}{|l|}{ Row } \\
\hline 5 & 81 & 59.94 & 485.51 & 76.14 & 1.06 \\
\hline 6 & 735 & 538.59 & $4,444.31$ & 830.94 & 0.88 \\
\hline 7 & 110 & 81.4 & 659.33 & 103.4 & 1.06 \\
\hline 8 & 229 & 169.46 & $1,372.60$ & 215.26 & 1.06 \\
\hline 9 & $1,308.00$ & 965.03 & $6,801.00$ & $2,269.67$ & 0.58 \\
\hline Subtotalc & $2,463.00$ & 1814.42 & $13,763.27$ & $3,495.41$ & 4.65 \\
\hline Total' & $2,708.71$ & $2,012.91$ & $15,110.64$ & $3,788.22$ & 8.22 \\
\hline Mean (SD) & 300.97 (438.7) & $223.66(322.48)$ & $1,678.96(2,348.70)$ & $470.82(772.7)$ & $0.91(0.16)$ \\
\hline
\end{tabular}

aRaw edible weights were calculated using edible yield percentage.

bone serving is a one-half cup for all vegetables except leafy greens, which is one full cup. The USDA recommendation for adults is two and one-half cups of vegetables or five cups of leafy greens per day.

'May not sum to total due to rounding.

\section{Discussion}

The results from this longitudinal pilot study demonstrate the potential production capabilities and harvest values of rural community gardens. During a single three-month growing season, the nine community gardens in this study yielded more than $2,700 \mathrm{lbs}$ of vegetables with an estimated value of more than $\$ 3,750$. Results also suggest production capabilities of rural community gardens can have potential nutritional implications for residents. When converted to serving sizes, this study's yield equated to more than 15,000 servings of vegetables which is enough for 33 adults to meet the USDA daily recommendations of two and one-half cups of vegetables or five cups of leafy greens per day [30] throughout the three-month growing season.

\section{Production capabilities}

\section{Harvest weights}

Researchers found few rural studies available for comparison. Nevertheless, the current study's harvest weight production capabilities were higher than the other rural study [5] found. In the current study, the average yield was $300.97 \mathrm{lbs}$ of produce in a single three-month growing season while the other rural study [5] reported an average yield of $128.00 \mathrm{lbs}$ of produce in a single four and a half month growing season. The current study's production capabilities also were greater than a previous urban community garden study in San Jose, California [4], which reported an average yield of $292.10 \mathrm{lbs}$ of produce in a single four-month growing season. These differences in harvest weights are most likely due to the greater size of rural gardens included in this study compared to those in the previous studies $[4,5]$. The gardens in this study averaged 8,978 sq ft while those in the rural Wyoming study [5] averaged $253 \mathrm{sq} \mathrm{ft}$. The California study [4] did not report an average size, but their garden plot sizes ranged from 100 to $600 \mathrm{sq} \mathrm{ft}$, which is less than the currents study's.
Compared to a study [6] of 67 community gardens totaling 1.7 acres in New York City [6], the current study's harvest weight production capabilities were much less despite having a greater total area of 1.85 acres. A factor which could contribute to this difference is urban community gardens usually employ bio intensive farming methods [4,6,31]. Bio intensive farming methods emphasize soil quality, utilize raised beds and high production techniques and promote the growth of high yield vertical crops, like tomatoes and beans $[4,6,31]$. These methods allow gardens to grow crops more efficiently in limited space and have been shown to increase average yields per square foot $[4,6,31]$. The rural raised bed and row gardens in the current study, however, more closely resemble large-scale industrial farming [31]. With more open space available in rural areas [32], there is less emphasis on producing high yields in a small area, even in the raised bed gardens. High availability of open space permits the growth of crops which require more space, like collard greens and sweet potatoes, therefore decreasing the yields per square foot. This is supported with the current study's results only reporting an average of $0.10 \mathrm{lb} / \mathrm{sq} \mathrm{ft}$ of produce in the raised bed gardens and $0.03 \mathrm{lb} / \mathrm{sq} \mathrm{ft}$ in the row gardens, for a total average of $0.05 \mathrm{lb} / \mathrm{sq} \mathrm{ft}$. In comparison, the urban studies in New York City [6] and in California [4], which both utilized bio intensive farming methods, reported $1.2 \mathrm{lb} / \mathrm{sq} \mathrm{ft}$ of produce and $0.75 \mathrm{lb} / \mathrm{sq} \mathrm{ft}$ of produce, respectively.

The current study's pounds per square foot results also were less than the other rural study [5], which reported $0.51 \mathrm{lb} / \mathrm{sq} \mathrm{ft}$ of produce. This difference could be due to the gardens in the Laramie, Wyoming, study [5] utilizing growing methods more similar to the bio intensive methods utilized by urban community gardens to help maximize their production capabilities in a challenging growing environment. In addition, this other rural study's [5] growing season was four and a half months, while the current study's was only three-months. 


\section{Harvest value}

Like production capabilities, there also were limited rural studies which reported specific data on the value of produce for rural community gardens. The current study's harvest value was \$0.91/ lb compared to $\$ 3.62 / \mathrm{lb}$ reported in the rural Wyoming study [5]. This difference is most likely due to different methods used to obtain price per pound data. In the current study, researchers used the USDA's report of average, nonorganic retail prices of produce in the Southeastern United States [29] or local, nonorganic store prices. In comparison, researchers in the Wyoming study [5] used local farmer's market prices or organic grocery store prices. Using farmers market and organic store food prices mostly likely increased the value of price per pound in the Wyoming study [5] as prices in these settings are typically higher compared to the nonorganic groceries used in the current study [33]. The current study's harvest value per pound also was less than other urban community garden studies who reported harvest values [4,6]. The New York City study [6] reported an approximate value of $\$ 2.44 / \mathrm{lb}$ during their growing season while the San Jose, California, study [4] reported $\$ 1.53 / \mathrm{lb}$. Researchers in the New York City study [6] used similar methods to the Wyoming study [5], and obtained price per pound values from local, organic grocery stores which most likely explains the difference from the current study's results. In the San Jose, California, study [4], researchers used the Bureau of Labor statistics for the Western region to determine price per pound of vegetables for four of the vegetables and then local, nonorganic grocery store prices for all other vegetables [4]. These methods are similar to the current study's, therefore the differences observed could be due to the difference in geographic locations where food costs are higher in the Western United States compared to the Southeastern United States [34]. In addition, in the both of the urban studies [4,6] tomatoes, which have a national nonorganic retail average price of $\$ 1.22 / \mathrm{lb}$ [29], were the highest yielded crop while in the current study greens, which have a national nonorganic retail average price of $\$ 0.98 / \mathrm{lb}$ [29] had the highest yield which could further explain the differences observed.

\section{Limitations and strengths}

Given the current study was a pilot study involving applied research, limitations are inherent. Unlike previous studies [46] which reported spring and summer production cycles, this current study used a fall production cycle. This most likely limited this study's crop variety, value and production capacity. Other limitations included diversity in garden size and use of both row and raised bed gardens, which made comparisons among gardens and other studies difficult. While the current study's garden diversity was a limitation, it is also the strength of the study. Unlike previous research [4-6], results from the current study are from six geographically different counties throughout the state rather than a single city. This increases representativeness and generalizability of the current study's results of rural community gardens' role in positively influencing accessibility and affordability of healthy food.

An additional strength of the current study was unlike the other rural study [5] which determined production capabilities in terms of serving sizes, the current study utilized edible yields when calculating serving sizes. Most harvested produce is not in the form it will be consumed. Often these foods need to be trimmed and cleaned to remove any pits, stems or other inedible portions. Edible yield provides researchers with the percent of a food item which consumers can eat and allows researchers to calculate how much of a raw food item is able to be consumed. By utilizing the edible yield, the serving size calculations in the current study represent edible servings. This makes the results more applicable to the potential nutrition implications of rural community gardens.

Increasing accessibility and affordability of healthy foods is especially important for rural residents who often have to travel further [20] and pay more for healthy food [22,23]. To further describe the capabilities of rural community gardens, future studies should seek to include a greater number of rural community gardens. With more gardens included, researchers should separate raised bed and row gardens as well as recognize if bio intensive farming methods were used to further compare the capabilities of these diverse types of gardens. Also, data should be collected across an entire year to understand seasonal and annual production capacities and harvest values. A better understanding of production capabilities and harvest values of rural community gardens is the first step to understanding community gardens' potential role in impacting rural population's overall nutrition and health.

\section{Conclusions}

The results from this pilot study suggest rural community gardens, by growing fresh vegetables, can increase accessibility and affordability of healthy food. During a three-month growing season, nine gardens in this study yielded $2,708.71 \mathrm{lbs}$ of vegetables valued at $\$ 3,788.22$. This equated to $15,110.64$ servings of vegetables, which is enough for 33 adults to meet the daily USDA recommendations throughout the three-month fall growing season. This data suggest rural community gardens also may have a role in improving overall health and nutrition of rural populations. Future studies are needed to determine rural community gardens' impact on fruit and vegetable consumption of the rural population who are more obese [18] and at higher risk for chronic disease [17] than their urban counterparts.

\section{Acknowledgements}

The authors gratefully acknowledge the contributions to this work by the Alabama Cooperative Extension System, Alabama Extension's Supplemental Nutrition Assistance ProgramEducation (SNAP-Ed) at Auburn University, Alabama Extension's High Obesity Program entitled Alabama Preventing and Reducing Obesity: Helping Engage Alabamians for Long-Term Health (ALProHealth) and the rural community gardens which participated.

\section{Funding/Financial Disclosures}

Funding for this research was provided by the Alabama Cooperative Extension System, the US Department of Agriculture's Supplemental Nutrition Assistance ProgramEducation and the Centers for Disease Control and Prevention High Obesity Program.

\section{Conflict of Interest Disclosure}

There are no conflicts of interest to report. 


\section{References}

1 Fowler MLC (1978) Growing with Community Gardening. Taftsville VT: Countryman Press.

2 Lawson LJ (2005) City Bountiful: A Century of Community Gardening in America. Berkley, CA: University of California Press.

3 https://communitygarden.org/resources/faq/

4 Algert SJ, Baameur A, Renvall MJ (2014) Vegetable output and cost savings of community gardens in San Jose, California. J Acad Nutr Diet 114: 1072-1076.

5 Conk SJ, Porter CM (2016) Food gardener's productivity in Laramie, Wyoming: More than a hobby. Am J Public Health 106: 854-856.

6 Gittleman M, Jordan K, Brelsford E (2012) Using citizen science to quantify community garden crop yields. Cities and the Environment (CATE) 5: 1-14.

7 Barnidge EK, Hipp PR, Estlund A, Duggan K, Barnhart KJ, et al. (2013) Association between community garden participation and fruit and vegetable consumption in rural Missouri. Int J Behav Nutr Phy 10 128.

8 Morton LW, Bitto EA, Oakland MJ, Sand M (2008) Accessing food resources: Rural and urban patterns of giving and getting food. Agr Hum Values 25: 107-119.

9 Sanchez EL, Liamputtong P (2017) Community gardening and healthrelated benefits for a rural Victorian town. Leisure Stud 36: 269-281.

10 Alaimo K, Packnett E, Miles RA, Kruger DJ (2008) Fruit and vegetable intake among urban community gardeners. J Nutr Educ Behav 40: 94-101.

11 Litt JS, Soobader MJ, Turbin MS, Hale JW, Buchenau M, et al. (2011) The influence of social involvement, neighborhood aesthetics, and community garden participation on fruit and vegetable consumption. Am J Public Health 101: 1466-1473.

12 Armstrong D (2000) A survey of community gardens in upstate New York: Implications for health promotion and community development. Health \& Place 6: 319-327.

13 Wakefield S, Yeudall F, Taron C, Reynolds J, Skinner A (2007) Growing urban health: community gardening in South-East Toronto. Health Promo Int 22: 92-101.

14 Park SA, Shoemaker CA, Haub MD (2009) Physical and psychological health conditions of older adults classified as gardeners or nongardeners. Hort Sci 44: 206-210.

15 Firth C, Maye D, Pearson D (2011) Developing community in community gardens. Local Environment 16: 555-568.

16 Saldivar-Tanaka L, Krasny ME (2004) Culturing community development, neighborhood open space, and civic agriculture: The case of Latino community gardens in New York City. Agr Hum Values 21: 399-412.

17 O'Connor A, Wellenius G (2012) Rural-urban disparities in the prevalence of diabetes and coronary heart disease. Public Health 126: 813-820.

18 Befort CA, Nazir N, Perri MG (2012) Prevalence of obesity among adults from rural and urban areas of the United States: Findings from NHANES (2005-2008). J Rural Health 28: 392-397.

19 Slavin JL, Lloyd B (2012) Health benefits of fruits and vegetables. Adv Nutr 3: 506-516.

20 Ver Ploeg M (2010) Access to affordable and nutritious food: measuring and understanding food deserts and their consequences: report to Congress. Diane Publishing.

21 Dean WR, Sharkey JR (2011) Rural and urban differences in the associations between characteristics of the community food environment and fruit and vegetable intake. J Nutr Educ Behav 43 : 426-433.

22 Garasky S, Morton LW, Greder K (2004) The food environment and food insecurity: Perceptions of rural, suburban, and urban food pantry clients in lowa. Fam Econ Nutr Rev 16: 41

23 Liese AD, Weis KE, Pluto D, Smith E, Lawson A (2007) Food store types, availability, and cost of foods in a rural environment. J Am Diet Assoc. 107: 1916-1923.

24 Hardin-Fanning F, Rayens MK (2015) Food cost disparities in rural communities. Health Promto Prac 16: 383-391.

25 Ratcliffe M, Burd C, Holder K, Fields A (2016) Defining Rural at the U.S. Census Bureau, ACSGEO-1. Washington, DC: U.S. Census Bureau.

26 Fu G (2006) Certificate of Calibration 007800-000-000. Huntersville, NC: Rubbermaid Commercial Product.

27 https://www.fns.usda.gov/tn/food-buying-guide-for-child-nutritionprograms

28 https://ndb.nal.usda.gov/ndb/

29 https://www.ams.usda.gov/market-news/retail

30 https://www.choosemyplate.gov/vegetables

31 Jeavons J (1995) How to Grow More Vegetables: Fruits, Nuts, Berries, Grains, and Other Crops. Berkeley, Calif: Ten Speed Press.

32 https://www.census.gov/prod/cen2010/briefs/c2010br-01.pdf

33 Carlson A, Jaenicke E (2016) Changes in Retail Organic Price Premiums from 2004 to 2010. United States Department of Agriculture, Economic Research Service (No. 242448).

34 https://www.bea.gov/data/prices-inflation/regional-price-paritiesstate-and-metro-area 